DOI: https://doi.org/10.24867/02HZ01Lucic

\title{
KOMPARATIVNA EVAULACIJA UTICAJA NA ŽIVOTNU SREDINU, UPOTREBA PRIMARNE I SEKUNDARNE PLASTIKE
}

\section{COMPARATIVE EVALUATION OF ENVIRONMENTAL IMPACT OF PRIMARY AND SECONDARY PLASTICS UTILIZATION}

\author{
Jovan Lučić, Nemanja Stanisavljević, Fakultet tehničkih nauka, Novi Sad
}

\section{Oblast - INŽENJERSTVO ZAŠTITE ŽIVOTNE SREDINE}

Kratak sadržaj - Osnovna svrha master rada je da se prikaže kako i na koji način plastika utiče štetno na životnu sredinu, da se na osnovu MFA analize i dostupne GaBi baze podataka prikaže koje vrste plastike najviše utiču na životnu sredinu, prilikom proizvodnje, insiniracije i reciklaže $i$ da se predstave mogući scenariji za rešavanje problema PET ambalaže u Srbiji.

Ključne riječi: Plastika, PET, MFA, LCA, GaBi, STAN, proizvodnja, insiniracija i reciklaža.

Abstract -The main purpose of the master's work is to show how does plastic pollute the ecosystem, and, based on the MFA analysis and the available GaBi databases, shows which types of plastics have the greatest impact on the environment, in production phase, incineration phase and recycling, and after that present possible scenarios for solving the problems of PET packaging in Serbia.

Keywords: Plastic, PET, MFA, LCA, GaBi, STAN, production, incineration and recycling.

\section{UVOD}

U poslednjih 60 godina, plastika je postala koristan i svestran materijal sa širokim spektrom upotrebe. Njena upotreba će se verovatno povećati sa tekućim razvojem u industriji plastike. U budućnosti plastika bi mogla pomoći u rešavanju nekih globalnih problema, kao što je na primer: plasatika se može koristiti za proizvodnju rotora za vetrogeneratore i tunele od polietilena koji mogu pomoći pri razvoju useva u inače nepovoljnim uslovima.

Staklena ambalaža više je od hiljadu godina bila odlično rešenje za čuvanje tečnosti. Međutim, moderno doba zahteva jeftiniju ambalažu, koja se lako transportuje i veće je zapremine. To je dovelo do razvoja plastične, posebno PET ambalaže. PET boce prilagođene su današnjem načinu života.

Svoju popularnost temelje na izvrsnoj prozirnosti, sposobnosti održavanja svežine (posebno gaziranih pića), maloj težini i nelomljivosti. Plastični materijali se već godinama sve više upotrebljavaju za izradu ambalaže, iako predstavljaju problem sa aspekta zaštite životne sredine.

\section{NAPOMENA:}

Ovaj rad proistekao je iz master rada čiji mentor je bio dr Nemanja Stanisavljević.
Razlozi za sve veću primenu su mnogobrojni. To su, između ostalih, niska cena sirovina, mala masa i različite mogućnosti prerade. Osim toga, specifični utrošak energije (utrošak energije po jedinici upakovanog proizvoda) pri proizvodnji plastičnih materijala, koji se koriste za izradu ambalaže, mnogo je manji nego što je pri proizvodnji npr. stakla ili aluminijuma.

Sve veća pažnja posvećena je plastičnom otpadu u celom svetu. Najveći uticaj za ovakvo otkriće imao je naučnik Čarsl Mur, koji je krajem devedestih otkrio veliki sloj otpada na putu između Kalifornije i Havaja. Tu veliku količinu otapda činile su plasatične flaše, kese, folije, velike bačene ribolovske mreže, kao i razne sitne čestice plastike. Ovaj tip "mase" može se nazvati "plastična supa". Isti problem je primećen u Evropi u Severnom moru. Nakon toga, nalazilo se sve više plastike u vodenim i kopnenim ekosistemima i na taj način problem plastike, je postao jedan od najvažnijih problema na globalnom nivou.

Plastika je relativno nov materijal, što znači da je problem plastičnog otpada tek nedavno nastao, i na taj način ne znaju se svi loši uticaji plastike na životnu sredinu.

Cilj ovog rada je da se prikaže kako i na koji način plastika utiče štetno na životnu sredinu, da se na osnovu MFA analize i dostupne GaBi baze podataka prikaže koje vrste plastike najviše utiču na životnu sredinu, prilikom proizvodnje, insiniracije i reciklaže i da se predstave mogući scenariji za rešavanje problema PET ambalaže u Srbiji.

\section{VRSTE PLASTIKE I KARAKTERISTIKE PLASTIKE}

Podela i označavanje plastičnih proizvoda je od izuzetnog značaja za sam proces recikliranja plastike, naročito za proces sortiranja, a zatim i za dalji tretman. Iako se u svetu koristi više sistema označavanja prema određenim standardima, može se reći da se svi oni uglavnom baziraju na standardu ISO 1043-1 i sa malim modifikacijama izgledaju kako je prikazano na slici 1 .

\section{PET-Polietilen Tereftalat}

Polietilen Tereftalat je polimer koji je oformljen kombinacijom dva monomera nazvani modifikovani ethylene glycol-A i prečišćena terephthalic kiselina-B. 


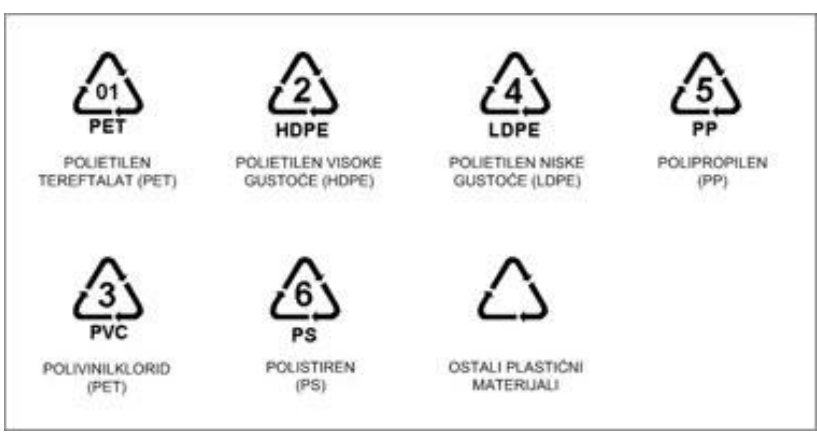

Slika 1. Simboli za označavanje plastike

Osobine: amorfan ili delimično kristalan prah bele boje, gustina 1330-1455 kg/m3, molarna masa 10.000 do $40.000 \mathrm{~g} / \mathrm{mol}$, otporan na dejstvo hladne vode, ulja, masti, nepolarnih i slabo polarnih rastvarača, neotporan na vruću vodu, vodenu paru, koncentrovane kiseline i baze, polarne rastvarače, poseduje dobre mehaničke osobine, otpornost na dejstvo svetla, dobre elektroizolacione osobine. (Nickolas, J. i dr. , 2010)

\section{HDPE - Polietilen Visoke Gustine}

Linearni polimer, High Density Polyethylene (HDPE) se pravi od etilena (ethylene) katalitičkim procesom. Definiše se gustinom većom ili jednakom $0,941 \mathrm{~g} / \mathrm{cm}^{3}$. HDPE ima nizak stepen grananja, karakteriše ga jača međumolekularna sila tj. zatezna snaga i potrebno je uložiti velike napore prilikom istezanja. Smanjenje grananja obezbeđuje se primenom odgovarajućih katalizatora i uslova prilikom polimerizacije. HDPE je neproziran i može da izdrži veće temperature, u odnosu na LDPE (može izdržati temperaturu od $120{ }^{\circ} \mathrm{C} \mathrm{u}$ kratkom periodu, a $110^{\circ} \mathrm{C}$ u stalnom zagrevanju).

\section{LDPE - Polietilen Niske Gustine}

To je rastegljiva smola bolja od HDPE u providnosti i jačini ali slabija u hemijskoj otpornosti. Prvi poliolefini su pravljeni pre oko pedeset godina polimerizaciom etilena pod visokim pritiskom. LDPE ima visok stepen kako kratkih tako i dugih lanaca što znači da lanci nisu efikasno upakovani u kristalnu strukturu. Ovo rezultuje manjom zateznom čvrstoćom i povećanom rastegljivošću. LDPE je korisna i široko primenjiva plastika. Delimično je providna ili neprovidna. Gustina se kreće u opsegu 0.910 - $0.940 \mathrm{~g} / \mathrm{cm}^{3}$.

\section{$P P$ - Polipropilen $\left(\mathrm{C}_{3} \mathrm{H}_{6}\right)$}

Polipropilen je linearni ugljovodonični polimer, izražava se kao $\mathrm{CnH} 2 \mathrm{n}$ (kao polietilen) i polibutan (PB) i predstavlja poliolefin ili zasićen polimer. Polipropilen je strukturno vinilni polimer, sličan je polietilenu osim što se za svaki drugi atom ugljenika u osnovnom lancu vezuje metil grupa. Polipropilen je izveden polimerizacijom propilena.

Osobine: čvrst polimer bez ukusa i mirisa, sa vrlo malom gustinom $\left(900-910 \mathrm{~kg} / \mathrm{m}^{3}\right)$, molarna masa $60000-200$ $000 \mathrm{~g} / \mathrm{mol}$, temperatura topljenja $164-170{ }^{\circ} \mathrm{C}$, izvaredna hemijska otpornost, poseduje dobre elektroizolacione i mehaničke osobine, visoko izražena hemijska otpornost.

\section{PVC-Polivinil Hlorid}

Strukturno PVC je vinilni polimer. Sličan je polietilenu samo što je svaki drugi ugljenični atom u kičmenom lancu zamenjen atomom hlora. Proizvodi se pomoću slobodnih radikala polimerizaciom vinila hlorida-D.

Osobine: čvrst beli prah, gustine 1350 - $1460 \mathrm{~kg} / \mathrm{m} 3$, molarna masa 50000 - $150000 \mathrm{~g} / \mathrm{mol}$, otporan na kiseline $\mathrm{i}$ baze, rastvorljiv $\mathrm{u}$ alkoholu $\mathrm{i}$ mnogim rastvaračima, omekšava na $92-94{ }^{\circ} \mathrm{C}$, a topi se na $170{ }^{\circ} \mathrm{C}$, poseduje dobre elektroizolacione $\mathrm{i}$ toplotno izolacione osobine.

\section{PS - Polistiren}

PS je vinilni polimer. Strukturno to je dugačak ugljovodonični lanac, sa fenilnom grupom na svakom drugom uglenikovom atomu. PS je proizveden pomoću slobodnih radikala vinilnom polimerizacijom od monomera stirena.

Osobine: čvrst amorfan prah, gustine 1052-1060 kg/m ${ }^{3}$, molarna masa 50000 - $200000 \mathrm{~g} / \mathrm{mol}$, otporan na soli i kiseline, neotporan na aromatične ugljovodonike, ketone, estre $\mathrm{i}$ aldehide, $\mathrm{u}$ benzinu bubri, čvrst poilstirol ima visoku zateznu čvrstoću, dobre elektroizolscione osobine, lako se prerađuje, omekšava već na $80^{\circ} \mathrm{C}$, a topi se na $170{ }^{\circ} \mathrm{C}$.

\section{EPS - Prošireni polistiren}

EPS - prošireni polistiren je izuzetno lagan proizvod koji je napravljen od proširenih polistirenskih perlica. EPS pena je više od $95 \%$ vazduha i samo oko $5 \%$ plastike.

Male čvrste plastične čestice od polistirena izrađene su od monomernog stirena. Polistiren je obično čvrsta termoplastika na sobnoj temperaturi koja se može rastopiti na višoj temperaturi i ponovo ojačati za željene primene. Proširena verzija polistirena je oko četrdeset puta veća od originalne granule stiropora.

\section{MATERIJALI I METODE}

Osnovna podrška pri izdradi rada je LCA alat GaBi - koji omogućava kreiranje određenih balansnih životnih ciklusa proizvooda i MFA alat STAN - koji omogućava primenu analize tokova materijala. Analiza životnog ciklusa (LCA) predstavlja ključni analitički instrument podrške strateškom upravljanju životnim ciklusom, pre svega, ali ne i samo proizvoda. (Antikainen, R., i dr., 2005). Naime, LCA je alat za procenu uticaja proizvoda na životnu sredinu. GaBi 4 je modulni sistem, to znači da planovi, procesi i tokovi, kao i njihove funkcije predstavljaju modulne jedinice, a kao rezultat toga, dobija se jasna $i$ transparentna struktura, koja čini ovaj program lakim za upotrebu. Podaci o LCA, LCI i LCIA i ponderisanim (,weighting“) modelima su pažljivo odvojeni jedni od drugih $\mathrm{i}$ zbog toga se vrši jednostavan proračun i upravljanje istim. GaBi 4 takođe omogućava modularni prikaz faza životnog ciklusa proizvoda. Pojedinačne faze (proizvodnja, upotreba i odlaganje) mogu se grupisati u kategorije i mogu da se obrađuju nezavino jedna od druge. MFA (analiza tokova materijala) predstavlja metodološki koncept koji se koristi za dizajniranje i pružanje informacija o antropogenim sistemima (antropogenom metabolizmu). (Bouman i dr.,1999) MFA je sistematska procena tokova i zaliha materijala u okviru sistema koji je definisan u prostoru i vremenu. Povezuje izvore, puteve, posrednu i finalnu dispoziciju materijala. Modeliranje u STAN softveru sastoji se od formiranja grafičkih modela koji sadrže tokove, procese i granice 
sistema, nakon čega se unose podaci o masenim tokovima, koncentracijama i transfer koeficijentima, za različite nivoe (nivo dobara, nivo supstanci), odakle se na kraju izračunavaju nepoznate koncentracije i tokovi.

\section{EVAULACIJA I DISKUSIJA}

Glavni problem istraživanja je štetan uticaj raznih vrsta plastike na životnu sredinu. Evaulacija je rađena $u$ programu $\mathrm{GaBi}$, koji svoje rezultate predstavlja pomoću 4 najvažnije kategorije opterećenja životne sredine, a to su:

- Globalno zagrevanje (GWP) [kg CO 2 eq.]

- Potrošnja energije (ADP fossil) [MJ]

- Potrošnja prirodnih resursa (ADP elements) [kg Sb. Eq.]

- Toksičnost za ljude (HTP) [kg DCB eq.]

Istraživanje je rađeno za 7 vrsta plastike (PET, HDPE, PVC, PP, PS, EPS, LDPE) i upoređivane su sve četiri kategorije opterećenja životne sredine za proizvodnju, insiniraciju i recikliranje.

Drugi deo istraživanja je sproveden u STAN-u i u njemu su predstavljena tri scenarija za tretman otpada. Biće prikazano trenutno stanje u Srbiji i biće predložena dva scenarija za moguće rešavanje problema odlaganja otpada.

\subsection{Evaulacija rezulata obrađenih u GaBi-ju}

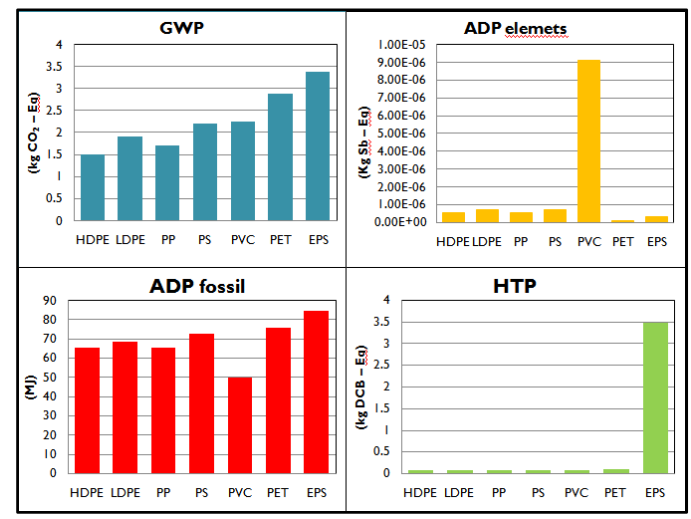

Slika 2. Uticaj plastičnih materijala na životnu sredinu $u$ fazi proizvodnje za $1 \mathrm{~kg}$ plastičnih materijala

Sa slike 2 može se videti da se kod globalnog zagrevanja (GWP), PET i EPS u fazi proizvodnje emituju naveće emisije $\mathrm{CO}_{2}$, a najmanje $\mathrm{kg} \mathrm{CO}_{2}$ eq, se emituje pri proizvodnji HDPE i PP. Što se tiše ADP elements PVC je jako dominantan. Za ljude je jako toksičan (HTP) EPS, a što se tiče potrošnje energije (ADP fossil) EPS je jako dominantan u odnosu na druge vrste plastike.

Metode za tretiranje otpada su: insiniracija ili spaljivanje, reciklaža, anaerobna digestija, mehaničko - biološki tretman otpada (MBT). Na slici 3 je prikazano koliko je 1 kg plastike obradjene insineracijom štetniji po životnu sredinu u odnosu na $1 \mathrm{~kg}$ proizvedene plastike. Korišćeni su podaci iz GaBi baze podataka za PP, PS, PVC primarnih materijala i upoređeni sa njihovim insineracijama.

Možemo videti kako je insineracija mnogo štetnija po životnu sredinu od proizvodnje samih materijala. Takođe možemo videti da su što se tiče GWP sva tri procesa insineracije slična pri opterećenju životne sredine ali što se tiče ADP elements, ADP fossil i HTP, tu je insineracija PVC-a mnogo štetnija po životnu sredinu od insineracije
PP-a i PS-a. Iako je insineracija štetna po životnu sredinu postoje druge prednosti kao sto je proizvodnja energije.

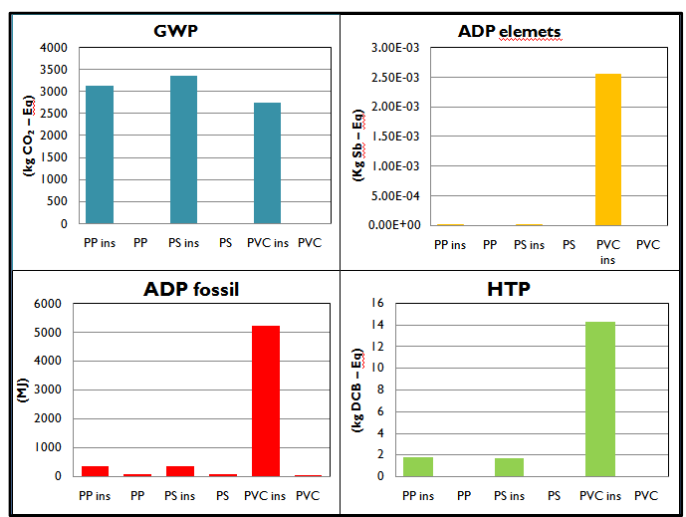

Slika 3. Poređenje primarnih materijala (PP, PS i PVC) sa njihovim insineracijama za $1 \mathrm{~kg}$

Bolje rešenje može biti recikliranje plastike i korišćenje sekundarnih sirovina. $\mathrm{Na}$ slici 4 je prikazano koliko zageđene po životnu sredinu ostvaruje $1 \mathrm{~kg}$ Primarnog PET-a i 1 kg Sekundarnog PET-a. Opet je korišćena GaBi baza podataka. U sve 4 kategorije uticaja na životnu sredinu možemo videti da je primarni PET mnogo dominantiji od sekundarnog.

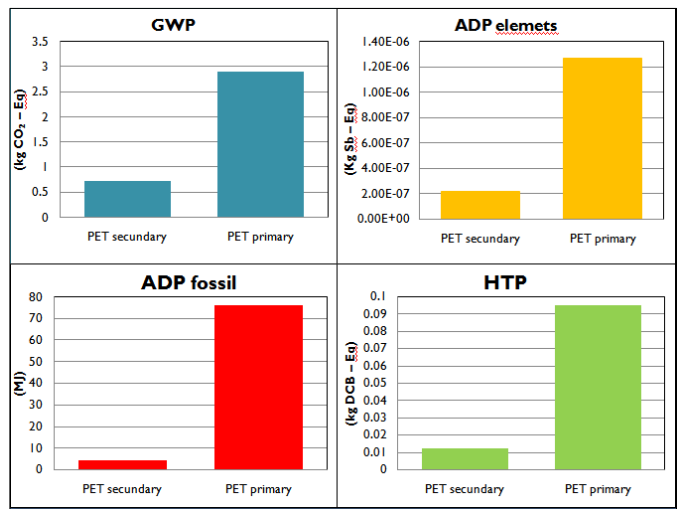

Slika 4. Odnos zagađivanja primarnog i sekundarnog PET-a za $1 \mathrm{~kg}$ materijala

\subsection{Reciklaža PET-a u Srbiji}

U Srbiji se na godišnjem nivou proizvede 100000 tona PET-a, a reciklira se samo 7000 tona, što predstavlja $7 \%$ od ukupne količine proizvedene PET ambalaže. Ostatak PET ambalaže završava pretežno na divljnim deponijama. U narednoj tabeli će biti prikazana dva scenarija, i njihovo zagađenje životne sredine preko 4 osnovne kategorije opterećenja životne sredine:

- I scenario je trenutno stanje u Srbiji, gde se reciklira 7\% PET ambalaže.

- II scenario je ukoliko se recikliranje PET amabalaže poveća na $15 \%$.

$\mathrm{Na}$ osnovu dobijenih rezultata iz tabele može se zaključiti da su vrednosti iz II scenarijo manji u odnosu na I scenarijo, i to nam pokazuje da ukoliko povećamo procenat reciklaže PET ambalaže samim tim ćemo smanjiti opterećenje po životnu srednu, što nam je i glavni cilj. 


\begin{tabular}{|c|c|c|c|}
\hline $\begin{array}{c}\text { Kategorije životne } \\
\text { sredine }\end{array}$ & $\begin{array}{c}\text { I scenarijo - } \\
\text { trenutno stanje }\end{array}$ & $\begin{array}{c}\text { II scenarijo - } \\
\text { buduće stanje }\end{array}$ & Razlika \\
\hline $\begin{array}{c}\text { Globalno zagrevanje } \\
\text { (GWP) [t CO } \text { eq. / god] }\end{array}$ & 279.600 & 262.000 & 17.600 \\
\hline $\begin{array}{c}\text { Toksičnost za ljude } \\
\text { (HTP) [t DCB eq. / god] }\end{array}$ & 8,94 & 8,3 & 0,64 \\
\hline $\begin{array}{c}\text { Potrošnja prirodnih } \\
\text { resursa (ADP elements) } \\
\text { [t Sb. Eq. / god] }\end{array}$ & 0,118 & 0,109 & 0,009 \\
\hline $\begin{array}{c}\text { Potrošnja energije (ADP } \\
\text { fossil) [MJ / god] }\end{array}$ & 738.300 & 713.500 & 24.800 \\
\hline
\end{tabular}

4.4. Razvoj mogućih scenarija za tretman PET ambalaže u Srbiji

U narednom poglavlju će biti prikazana tri scenarija za tretman otpada. Biće prikazano trenutno stanje u Srbiji i biće predložena dva scenarija za moguće rešavanje problema odlaganja otpada. U prvom scenariju biće prikazano stvarno stanje u Srbiji, gde imamo proces recikliranja i odlaganje otpada na sanitarne i divlje deponije.

\subsubsection{I scenario - Trenutno stanje u Srbiji}

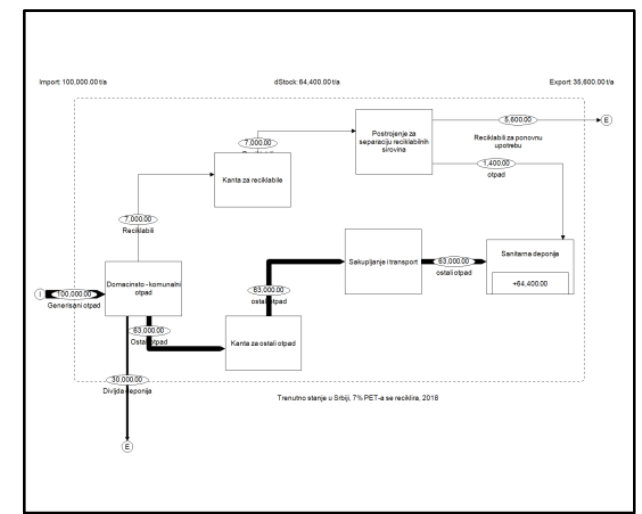

Slika 5. I Scenario - Trenutno stanje sistema za upravljanje PET - ambalažnim otpadom u Srbiji

U Srbiji se godišnje generiše 100.000 t PET ambalaže, od čega se organizovano sakuplja 70.000 t a ostatak završava na divljim deponijama. Od ukupne količine sakupljenog otpada 7.000 t ide u postrojenje za reciklažu, a ostatak ide na sanitarne deponije.

Nedostaci trenutnog sistema su:

- Ne postoji primarna ni sekundarna separacija otpada.

- Dotrajala mehanizacija za sakupljanje otpada.

- Neodgovarajući broj i loše stanje kontejnera.

- Svest ljudi o odlaganju otpada na divlje deponije nije na odgovarajućem nivou.

- Mali broj sanitarnih deponija.

\subsubsection{II scenario - Razvoj najrealnijeg scenarija sa ciljem tretmana PET ambalažnog otpada recikli- ranjem i odlaganjem na sanitarne deponije}

U ovom scenariju najvažnije je osloboditi se divljih deponija, što je prema ovom scenariju učinjeno. Može se videti da $25 \%$ od ukupnog generisanog otpada ide na recikliranje što je realno. Takođe se može videti da veći broj otpada ide na sanitarne deponije, što je opet izvodljivo sa otvaranjem novih sanitarnih deponija u Srbiji. Ovaj scenarijo je izvodljiv ukoliko se uloži određena količina novca da se naprave postrojenja za reciklažu i da se otvore nove sanitarne deponije.
Najveća prepreka ka ostvarenju ovog cilja jeste svest ljudi. Jedini način da se podigne svest ljudi, jeste da se pojedinci koji nepropisno odlažu otpad na divlje deponije kazne sa velikim novčanim kaznama i na taj naćin da se utiče na svest ljudi. Zatim svest se može podizati držanjem prezentacija, postavljanjem plakata, javim nastupima preko medija...

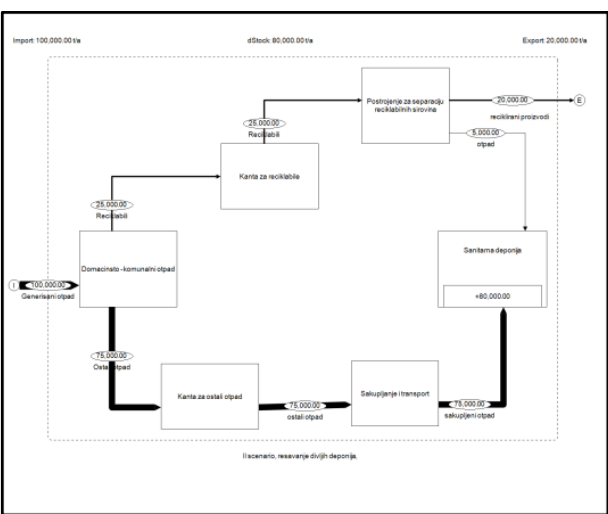

Slika 6. II scenario - Najrealniji mogući scenario za Srbiju

4.4.3. III scenario - Razvoj scenarija sa ciljem tretmana PET ambalažnog otpada i reciklabilnih materijala uključujući MBT postrojenje

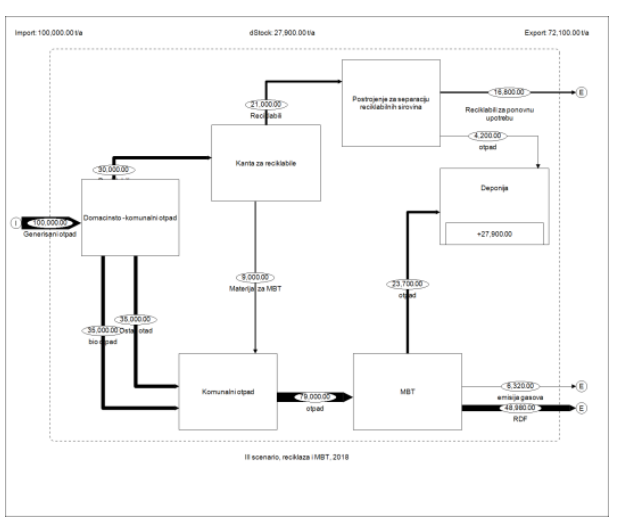

Slika 6. III scenario - Mogući scenarijo sa MBT postrojenjem i postrojenjem za recikliranje

Trećina komunalnog otpada iz domaćinstva koga ima sve zajedno 100.000 t, odlazi u kantu za recikliranje, 30.000 t. Jedan deo iz kante za recikliranje ide u postrojenje za separaciju reciklabilnih sirovina, $21.000 \mathrm{t}$, iz koga jedan deo izlazi u vidu reciklabila $16.800 \mathrm{t}$ a ostatak od $4.200 \mathrm{t}$ se odlaže na deponiju, dok drugi deo završava u komunalnom otpadu, $9.000 \mathrm{t}$.

Druga trećina predstavlja ostali otpad 35.000 t i ide direktno u komunalni otpad, kao i treća trećina završava koja predstavlja bio-otpad koji takođe završavca direktno u komunalnom otpadu. Iz komunalnog otpada, otpad se u količini od 79.000 t se plasira u MBT postrojenje. Manji deo u količini od 23.700 t odlazi na deponiju, dok se veći deo konvertuje u gorivo, RDF u količini od 55.300 t. Ovaj scenario je moguće ostvariti, ukoliko se povećaju plate $u$ Srbiji i samim tim ljudi budu mogli da putem informatike izdvoje veću količinu novca za tretman otpada. 


\section{ZAKLJUČAK}

Reciklaža plastičnog otpada predstavlja jedan od načina za rešavanje problema otpada nakon upotrebe. Povećanjem ekonomske dobiti, ekološke svesti i razvojem novih tehnologija došlo se do značajnog povećanja stope iskorišćenja i reciklaže plastičnog otpada.

Ovi trendovi verovatno će se nastaviti, ali neki značajni izazovi i dalje postoje, kako tehnološki tako i ekonomski, kao i pitanje društvene svesti.

Povećanje stope reciklaže plastičnog otpada, i samim tim smanjenje otpada na deponijama, moguće je postići širenjem spektra prikupljanja otpadne ambalažne plastike, otpadne plastike iz domačinstva. Zajedno sa naporima da se poveća korišćenje reciklirane plastike kao zamene za primarnu plastiku, reciklaža otpadne plastike doprinosi i smanjenju negativnog uticaja industrije polimera na životnu sredinu.

Zbog činjenice da naš život zavisi od okruženja, treba razmatrati pitanje izbora tretmana reciklaže otpadne plastike na međunarodnom nivou, jer svako nosi odgovornost i ima obavezu da se pridruži i pomogne u nastojanju da se program za reciklažu plastike što više razvije.

$\mathrm{Na}$ osnovu evaulacije rezultata može se zaključiti da prilikom proizvodnje plastičnih materijala dolazi do velikog zagađenja životne sredine u sve četiri navedene kategorije, kao i da se prilikom insiniracije mnogo više zagađuje životna sredina, jer dolazi do emitovanja emisija štetnih gasova u atmosferu.

Ekološki posmatrano, predloženi program reciklaže PET ambalaže nije zagađivač, jer se kao energent koristi samo električna energija. U procesu proizvodnje ne dolazi do stvaranja tehnoloških otpadnih voda, dok se sanitarne vode ne otpuštaju u septičke jame ili kanalizaciju. Tokom proizvodnog procesa vazduh se ne zagađuje, a stvara se buka niskog intenziteta.

Sem reciklaže, jedan od načina rešavanja problema zagađivanja je i upoznavanje građana sa i podizanje nivoa svesti o posledicama zagađivanja.

U tu svrhu je veoma važno obavestiti stanovništvo sa aktivnostima u njihovom regionu preko postera $\mathrm{u}$ lokalnim trgovinskim centrima i marketima, preko letaka koji se stavljaju u sandučiće i anketnih listića koji se nude meštanima.
$\mathrm{Na}$ osnovu datih informacija i scenarija, može se zaključiti da je po pitanju reciklaže PET ambalaže Srbija među najgorim zemljama na svetu. Da bi se popravilo to stanje, potrebno je imati novac za izgradnju novih postrojenja za reciklažu i otvaranje novih sanitarnih deponija, ali najvažnije je promeniti svest ljudi o odlaganju otpada na divlje deponije. Ukoliko svaki čovek pravilno odlaže otpad i razdvaja ga u svom domaćinstu mnogo pomaže prilikom krajnjeg tretmana otpada.

\section{LITERATURA}

[1] Nickolas, J.; Themelis, Lj. A. Identification and Assessment of Available Technologies for Materials and Energy Recovery, Report submitted to Flexible Packaging Association, New York City, October 25, 2010.

[2] Antikainen, R., Dahlbo, H., Melanen, M., Ollikainen, M. (2005). 6.3. Decision support approaches: life cycle assessment (LCA) and substance flow analysis (SFA). Jalkanen, A. Nygren,P. (eds.) Sustainable use of renewable natural resources - from principles to parctices. University of Helsinki Department of Forest Ecology Publications 34, 1-17.

[3] Bouman, Mathijs, Heijungs, Reinout, Van der Voet, Ester, Van den Berghb, Jeroen C. J. M. i Gjalt Huppes. 1999. "Material flows and economic models: An analytical comparison of SFA, LCA and equilibrium models", Ecological Economics 32 (2000)

\section{Kratka biografija:}

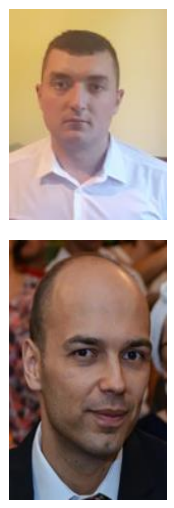

Jovan Lučić rođen u Mostaru, BiH, 1991.godine. Master rad na Fakultetu tehničkih nauka iz oblasti Inženjerstvo zaštite životne sredine - Analiza tokova materijala, odbranio je 2018.god.kontakt: jovanlucic1991@gmail.com

Nemanja Stanisavljević, vanredni profesor na Fakultetu tehničkih nauka, doktorirao je 2013. na Fakultetu tehničkih nauka u Novom Sadu. Postdoktorsko usavršavanje je relizovao kao Fulbrajtov stipendista u SAD-u, na Državnom Univerzitetu Severne Karoline, Departmanu za mašinstvo, građevinu i inženjerstvo zaštite životne sredine. Od 2015. godine izvodi nastavu kao gostujući profesor na Tehničkom Univerzitetu u Beču, Austriji. 